\title{
Comparison Indonesian and Australian Students' Cultural Intelligence and Attitude towards Teamwork: Case study of Institut Teknologi Bandung and Griffith University
}

\author{
Nur Arief Rahmatsyah Putranto ${ }^{a}$, Peter Woods ${ }^{b}$
}

${ }^{a}$ School of Business and Management, Bandung Institute of Technology, Bandung 40132, Indonesia ${ }^{b}$ International Business and Asian Studies Department, Griffith University, Nathan QLD 4111, Australia

*Corresponding author: nur.arief@sbm-itb.ac.id

\begin{abstract}
As business world becomes more competitive, the person's ability to work individually and in team become the important factor to win the competition. In addition, the effects of globalization have raised company awareness of the importance of multicultural teams in gaining a global competitive advantage. Therefore, it becomes one of universities' role to prepare the students with ability to work in multicultural team. This research want to compare the cultural intelligence (CQ) and students' attitude towards teamwork between Indonesian and Australian students with Institut Teknologi bandung and Griffith University students as respondents. The result showed that there is significant difference between Australian and Indonesian students for CQ and attitude towards teamwork where for CQ Indonesian students showed higher mean for both CQ and attitude towards team work..
\end{abstract}

Keywords: Cultural intelligence, attitude toward teamwork, Indonesian students, Austalian students

(C) 2016 Penerbit UTM Press. All rights reserved

\subsection{INTRODUCTION}

The concept of intelligence is not a new concept. In today's business world, in order to become competitive and innovative, organizations need to have employees that can work together to solve problems (Gardner \& Korth, 1998). Therefore, a person's ability to work in teams may be as important as their task related work skills. In addition, the effects of globalization have raised company awareness of the importance of multicultural teams in gaining a global competitive advantage. Thus, universities have an important role in providing their students with the ability to work together in a team, whether a monocultural or multicultural group, so they are adequately equipped in the business world (Huddleston \& Pfaff, 2003; Kaenzig, Hyatt \& Anderson, 2007). In addition, globalization has led many universities and companies to recruit from all over the world to make the workplace more diverse, thus increasing the possibility for individuals to work in a multicultural team.

For students, working in groups can help them in learning how to deal with different people, develop opinions and ideas, learn to respect and trust others, and learn to work in collaborative ways (Huddleston \& Pfaff, 2003). Even though in universities academic excellence is based on individual achievement, however the use of cooperative learning can increase individual achievement further than individual or competitive learning (Johnson, Johnson, \& Smith, 1998). However, not all teams can work collaboratively to achieve desired outcomes. This can be caused by several factors and one may be the individual attitude towards teamwork.

Working in teams does not always result in success despite the potential benefits, as working in teams may produce problems distinct from working individually (McCorkle et al., 1999). Additionally, working in multicultural teams can have more problems compared to teams with members from the same cultural background (Scholl, 2009). Every individual has their own set of experiences, beliefs, perceptions, and expectations in addition to differences in their skill, knowledge, and behaviour that they bring to the team process. These differences can affect the individual in the team as well as various aspects of the team such as team interaction and performance (Freeman, 1996).

However, not every individual likes working in teams as they may have better performance when they work individually. An example of this would be people who have a strong need for achievement (Freeman, 1996). If there is no good reason for individuals with a strong need for achievement to benefit from a group, then these people will tend to reject the group and this may impact team relationships and performance (Freeman, 1996).Another problem is where the team membersare only interested in their task that can barrier them to get knowledge and skill from other member's task that are not related with their job (Huddleston \& Pfaff, 2003).

There are a lot of factors that can influence attitudes towards teamwork. One of them are cultural intelligence (CQ). Early and Ang (2003) defined cultural intelligence as "a person's capability to adapt effectively to new cultural contexts". Therefore, the higher individual's CQ may make it easier for them to adapt to a multicultural team.

However, to date, very little research in CQ and attitude towards teamwork has been published in this field with Indonesians as a sample. Also, there is relatively little research comparing Indonesians with other nationalities. Therefore this research will try to use two countries, Indonesia and Australia, as samples and then compare them to determine whether there are differences or not between the two countries. 


\title{
2.0 THEORETICAL FOUNDATION OF THE STUDY
}

\author{
The Cultural Intelligence
}

\section{Cultural Intelligence Definition}

Before Early and Ang (2003) developed the model of CQ, the concept of CQ had already been introduced by several scholars as the intelligence concept that incorporates the aspect of culture (Scholl, 2009). However, as no model was developed to measure CQ, not much attention was paid to CQ until Early and Ang (2003). They developed the model of CQ from the multiple intelligence concept developed by Gardner (Scholl, 2009). The model explained why some individuals can adapt successfully when they are in different cultural environments and their model incorporates four components; metacognition, cognition, motivation, and behaviour (Ang et al, 2007). In recent years, researchers have paid increasing attention to explore the concept of CQ.

There are several definitions of CQ. Earley and Ang (2003) defined CQ as "a person's capability to adapt effectively to new cultural contexts" whereas Earley and Mosakowski (2004, p. 140) defined it as "an outsider's seemingly natural ability to interpret someone's unfamiliar and ambiguous gestures the way that person's compatriots would". Another definition was proposed by Peterson (2004, p. 89) which defined CQ as "the ability to engage in a set of behaviors that uses skills (i.e. language or interpersonal skills) and qualities (e.g. tolerance for ambiguity, flexibility) that are tuned appropriately to the culture-based values and attitudes of the people with whom one interacts". In line with this, Thomas (2006, p. 80) defined it as "the ability to interact effectively with people who are culturally different". Moreover, Ang and colleagues (2007, p. 337) defined CQ as "an individual's capability to function and manage effectively in culturally diverse settings". Finally, Ekelund and colleagues (2008, p. 126) have defined CQ as "a system of interacting knowledge and skills, linked by cultural metacognition that allows people to adapt to, select, and shape the cultural aspects of their environment". Even though there are a lot of definitions, basically it is about an individual's capability to adapt and interact with other people from different culture backgrounds. The difference between definitions is in terms of the components that form CQ. This will be discussed in the next section. However, the indicator of effective CQ is similar between definitions and this is effective intercultural interactions (Ekelund et al., 2008). Effective intercultural interactions have the following characteristics: good personal adjustment that is indicated by feeling comfortable and less stressed when interacting with people from different cultures, good interpersonal relationships with people from different cultures, and the effective completion of task-related goals (Ekelund et al., 2008).

This research will use the definition of CQ adopted from Ang et al. (2007) because it explains not just about the capability of someone to understand different cultures but it also explains how CQ includes a person's attitude, behaviour, and interaction with other people from different cultures that in line with what this research's purpose.

\section{Cultural Intelligence Components}

Based on different scholars, the components of CQ can vary. Early and Ang (2003) explained that people need different skills and capabilities compared with when they interacted only with people from their own cultural context. These skills and capabilities consist of: cognitive which includes metacognition, declarative versus procedural knowledge, reasoning (inductive and analogical), and social perception related to reasoning; motivational which includes efficacy expectations that provide energy to set and chase personal goals and increase the efforts if it has a potential to failure; and goal setting that provide the guidance and intrinsic challenge needed for exploring into the cultural environment; behavioural which includes self-presentation to present themselves to others in favorable manner and impression management to be able to adapt more effectively through increasing someone's knowledge about the presentation rules required in various culture as well as produce and modify verbal and nonverbal behaviours consistent with those cultural norms.

In line with that, Earley and Mosakowski (2004) divided CQ components into three factors: the cognitive (head), the physical (body); and the emotional/motivational (heart). The cognitive (head) aspect is about learning beliefs, customs, and taboos of foreign cultures as well as finding ways to adapt better into the new culture and environment. The physical (body) aspect is about actions and behaviours that imitate the gestures and customs of people in new environment to have good interaction with them. The emotional/motivational (heart) aspect is about confidence and believing in their own-efficacy to adapt to new culture that involve overcoming obstacles and hindrances.

A little different with that, Thomas (2006) proposed three components of CQ: knowledge, mindfulness, behaviour that coagulate to create the ability to interact effectively across cultures. The first component, knowledge, is the essential principle in cross-cultural interaction that helps a person know what culture is, how cultures vary, and how culture affects behavior. This knowledge consists of content knowledge, process knowledge, cognitive influence, and motivational influence. Second component, mindfulness, is the key in linking between the knowledge and actions which creates heightened awareness of and enhanced attention to current experience or present reality. Awareness means fundamental aspect of consciousness and is the constant observing of someone's internal condition and external environment, where attention means increased sensitivity to a limited range of motivations. Third component, behavioral, is the ability to produce appropriate mannerisms in new cultural settings based on knowledge and mindfulness. Therefore, rather than change the behavior to adapt with new culture, this component involves choosing or creating the appropriate behavior that meets the expectations of people from different cultures and intercultural situations.

Moreover, Ekelund and colleagues (2008) also proposed three components of CQ: Cultural Knowledge, Cross-cultural skills, Cultural metacognition. Cultural knowledge refers to content knowledge in cultural area which is the foundation that forms the basis for understanding and interpreting the behavior of others and ourselves. This knowledge consists of the knowledge about cultural identities, values, attitudes, and practices to make accurate and effective intercultural behavior. Cross-cultural skills refer to the skills that someone needs to be able to have effective interaction in intercultural situations by learning from social experiences by paying attention to and appreciating differences in cultures between oneself and others. These skills consist of perceptual skills (e.g. open-mindedness, tolerance of uncertainty, and being non-judgmental), relational skills (e.g. flexibility, sociability, and empathy), and adaptive skills (e.g. self-monitoring, behavioral flexibility, and self-regulation). Cultural metacognition is knowledge of and control over one's thinking and learning activities. This metacognition involves: "cultural metacognitive monitoring" which is attention to conscious cognitive experience, as well as to affective and personalmotivational states with regards to the cultural setting that determines the course of a strategy in intercultural interaction; and "cultural 
metacognitive regulation". These involve methods that are used to self-regulate and control cognitive activities and ensure that a cognitive objective has been met.

Additionally, Ang and colleagues' (2007) stated that CQ has four elements; metacognitive intelligence refers to mental processes that individuals use to acquire and understand cultural knowledge, including knowledge of and control over individual thought processes relating to culture, cognitive intelligence refers to knowledge of the norms, practices and conventions in different cultures acquired from education and personal experiences, motivational intelligence refers to the capability to direct attention and energy toward learning about and functioning in situations characterized by cultural differences, and behavioural intelligence refers to the capability to exhibit appropriate verbal and nonverbal actions when interacting with people from different cultures.

\section{Attitude towards Teamwork}

An attitude can be defined as a collection of feelings and beliefs (Waddell et al., 2011). The attitude towards teamwork is defined as the individual's willingness to continue working together with the same team as well as in other teams (Gardner \& Korth, 1998). Hence, beliefs, attitudes, and values of individuals who collectively form the standards and aspirations of the team can have direct implications for both individuals in the group and for the group as whole (Freeman, 1996).

Previous research has demonstrated the importance of attitudes towards teamwork (Freeman, 1996; Huddleston \& Pfaff, 2003; Bianey, Ulloa, \& Stephanie, 2004). However, the results were somehow contradictory. For example some research showed that even though the members of teams have a positive attitude towards teamwork but the result not really significant meanwhile team with members that prefer to work individually can give better result (Gardner \& Korth, 1998; McCorkle, 1999; Bianey et al., 2004)

McCorkle et al. (1999) stated that the attitude towards teamwork can be affected by the team itself. Team dynamics and team complexity can result in either a positive or a negative attitude towards teamwork and this can affect team performance (Bianey et al., 2004). Teams that can give benefits to its members, such as improved individual skill, reduced workload, or help to complete complex tasks, can make the attitude become positive. Teams that have problems, such as free riding, inadequate rewards, member skills and attitude problems, transaction-cost problems, can make the members have negative attitudes towards teamwork (McCorkle et al., 1999).

There are several factors that can affect someone's attitudes towards teamwork. Freeman (1996) explained that individual factors such as am individual's values, beliefs, and attitudes can affect both the individual and the team. Additionally, the characteristics of the teams and the members, such as common goals, common standards, common interests, common knowledge, time spent together, inter-dependent task, can affect the attitude towards teamwork(Freeman, 1996). Individual's needs can also affect someone's attitude towards teamwork. For example a person with high needs of achievement will be most likely to choose to work individually especially if he/she has the skills and ability whereas person with high need of social interaction will prefer to work in a team (Lawler, 1986). The role of members in team (leader or follower) can also affect the attitude towards teamwork. For example, an informal leader in a team will feel that they need to contribute to the team and this leads to a positive attitude towards teamwork(Pescosolido, 2001). Team size also can affect the members' attitude towards teamwork(Ingham, Levinger, Graves, \& Peckham,1974). Another factor that can affect attitude towards teamwork is the culture where people from countries with an individualist culture are most likely to work individually whereas people from collectivist culture will love to work in team (McCorkle et al., 1999). The other factors are rewards that team members receive, perception of workload, peer reviews/evaluation, and the existence of free-riders (Huddleston \& Pfaff, 2003).

\section{Team and Culture}

Culture can affects the effectiveness of teams. Even before the team is formed, culture can affect the individual's attitude towards teamwork. Individuals from countries with high individualism will have a relatively high resistance to work in teams and self-management in teams while, on the other hand, individuals from high collectivism will have a lower resistance both to work in teams and self-management in teams that can lead to effectiveness of team performance (Kirkman \& Shapiro, 2001). However, situations and conditions could potentially be a moderator to this attitude towards teamwork(Gelfand et al., 2007). For example, an American may have a negative attitude towards teamwork if their individual performance is better than their team performance (Gelfand et al., 2007). Australians may accept the changing of team membership during team processes while Taiwanese will find this hard because they think that the relationship among group members will disrupted (Harrison, McKinnon, Wu, \& Chow,2000). Individuals from high individualism cultures may have a more positive attitude towards teamwork if they have reward systems based on individual performance, while individuals from collectivist countries will feel less obligated in the same situation (Ramamoorthy \& Flood, 2002).

Not only can culture affect the attitude towards teamwork, but it can also affect team processes (Gelfand et al., 2007). Teams with majority members from collectivist culture can have good cooperation and can enhance team performance (Eby \& Dobbins, 1997). However, team with members from individualistic cultures will not always have bad team performance. Team with members from collectivist cultures can have good performance if they have high goal sharing, concern of group identity, and affect based trust, where team with members from individualistic cultures can have good performance if they have high goal interdependence, concern of personal identity, and cognitive based trust (Gelfand et al., 2007).

The way teams define their success and efficiency is different across cultures. For example people in Mexico may think that the socioemotional behavior among its group members is important to achieve the success of the team where Anglos have different thinking by perceiving that socio-emotional behavior not too important but achieving task objective is how they define the success of teams (SanchezBurks, Nisbett \& Ybarra, 2000; G Gelfand et al., 2007). Culture also can moderate the motivation amongst their group members that can impact group performance. Individuals in collectivist countries may have more group efficacy and will give better group performance compared to individuals from individualistic countries (Gelfand et al., 2007). Despite that, the difference in situations and conditions can also affect the development of team processes in different cultures. For example, job complexity and autonomy can give positive impact into team development in United States while job enrichment can give negative effect to team development in high power distance groups (Man \& Lam, 2003; Drach-Zahavy, 2004). Moreover, Yuki, Maddux, Brewer, and Takemura(2005) argued that trust between group members can be formed in different ways based on culture. In the United States the group members will have more trust if they are from the same category, such as the same school, whereas in Japan, trust amongst members can be developed if they have indirect connections with others. 
Regardless, of the differences in the cultures, many researchers argued that multicultural teams can have strategic advantages for organization (Gelfand et al., 2007). However, some researchers had also argued that the differences in team member culture can lead to a lot of problems that can affect cohesiveness of the teams (Gelfand et al., 2007). Nevertheless, these problems can be overcome to have multicultural teams that can have good performance. For example, through good leadership, the leader can prevent the problems associated with communication and knowledge sharing among team members (Ayoko, Härtel, \& Callan, 2002; Baba, Gluesing, Ratner, \& Wagner, 2004). Another way is by forming multicultural teams where there are no majority or minority members that coming from the same culture because this situation can increase the probability that cultural identity will become obvious that can be the initial of a lot of problems (Randel, 2003). Moreover, Earley and Mosakowski (2000) stated that highly diverse teams can outperform moderately diverse teams because they can avoid the creation of subgroup cultures that can obstruct the team cohesiveness.

\section{Australian and Indonesian Culture}

The Republic of Indonesia or Indonesia, is a country in Southeast Asia that has more than 17,000 islands and consists of 33 provinces. Based on the 2010 national census, the population in Indonesia is around 237.6 million with around 300 distinct native ethnic groups that consist of Javanese 45\%, Sundanese 14\%, Madurese 7.5\%, Coastal Malays 7.5\%, Chinese 3.7\%, Batak 3\% and other ethic groups 19.3\% (Overview of Indonesia, 2012; Jakarta Post, 2012). The national language of Indonesia is Bahasa Indonesia which developed from Malay trade dialect that used throughout the region in the past (Overview of Indonesia, 2012). However, besides Bahasa Indonesia, Indonesia has more than 300 different regional languages and dialects (Overview of Indonesia, 2012). In terms of religion, Indonesia acknowledges 5 religions which are Muslim, Protestant Christian, Roman Catholic Christian, Hindu, and Buddhist whereas Islam is the majority religion with around $88 \%$ of the Indonesian population, then 10\% for both Protestant and Roman Catholic Christian, and only 2\% are Hindu and Buddhist.

In terms of Hofstede's cultural values, Indonesia scores 78 for Power distance which means the characteristic of Indonesian people are being dependent on hierarchy, unequal rights between power holders and non-power holders, superiors in-accessible, leaders are directive, management controls and delegates (Hofstede, 2012). The communication between leaders and their subordinates is prefer indirectly and negative feedback especially about leader is hidden (Hofstede, 2012). Also the subordinates expect to be clearly told what, how, and when to do by the leaders (Hofstede, 2012). For Individualism, Indonesia only scores 14 which indicate that Indonesia has a collectivist society (Hofstede, 2012). This means that individuals are expect to follow to the rules of the society they belong and also they have a tendency to care with others. For example, the children in Indonesia have a desire to make their parents' life easier and want to take care of their parents in their old age (Hofstede, 2012). Indonesia score 46 for Masculinity and this is considered low Masculinity (Hofstede, 2012). This means the focus in Indonesia is on "working in order to live" while leaders attempt for harmony, people value equality, has strong solidarity, conflict are resolved through compromise and negotiation, and focus on well-being (Hofstede, 2012). In terms of Uncertainty Avoidance, Indonesia scores 48 that indicates has a medium low preference for avoiding uncertainty (Hofstede, 2012). This means that in Indonesia maintaining the work place and relationship in harmony is looking as important matters (Hofstede, 2012). Therefore, people in Indonesia is not likely to show their negative emotion or anger externally and the way they do conflict resolution is preferable indirectly such as using third party intermediary (Hofstede, 2012).

Meanwhile, Commonwealth of Australia known as Australia is a country that consists of the mainland of Australia continent, the island of Tasmania, and many small islands. Based on the 2011 national census, the population in Australia is around 21.5 million people that based on ancestry of English 36.1\%, Australian 35.4\%, Irish 10.4\%, Scottish 8.9\%, Italian 4.6\%, German 4.5\%, Chinese 4.3\%, Indian 2\%, Greek $1.9 \%$, and Dutch 1.7\% (Australian Bureau of Statistics, 2012). For language, the majority of population in Australia uses English as their communication language (80.7\%) (Australian Bureau of Statistics, 2012). However, there are also other languages that people in Australia use which are Mandarin (1.7\%), Italian (1.5\%), Arabic (1.4\%), Cantonese (1.3\%), Greek (1.3\%), Vietnamese (1.2\%), Spanish (0.6\%), Hindi $(0.5 \%)$, and Tagalog $(0.4 \%)$ (Australian Bureau of Statistics, 2012). In terms of religion, the majority of Australian's religion is Christian $61.1 \%$ (consists of Catholic, Anglican, Uniting Church, Presbyterian and Reformed, Eastern Orthodox, Baptist, Lutheran, Pentecostal, and other Christians), where non-Christian religion reaches 7.2\% (consists of Buddhist, Islam, Hinduism, Judaism, and other religions) and 22.3\% of people state no religion (Australian Bureau of Statistics, 2012).

In terms of Hofstede's cultural values, Australia scores only 36 for Power Distance which means hierarchy is only for convenience, superiors are always available, managers rely on individual employees' expertise, information is shared frequently, and communication is preferable informal, direct, and participative (Hofstede, 2012). For Individualism, Australia scores 90 which indicate that Australia has a highly individualistic atmosphere (Hofstede, 2012). This means that people in Australia are expected to look after themselves and their immediate families, also for employees, they are expected to be self-reliant and display initiative because the promotion decision is based on merit and performance (Hofstede, 2012). Masculinity reaches 61 for Australia which is considered as masculine society (Hofstede, 2012). This means that Australian people behave to successes and achieve high achievement because it becomes a basis for hiring and promotions in workplace and also the way Australian resolved conflict at in individual level and the goal is to win (Hofstede, 2012). In terms of Uncertainty Avoidance, Australia score 51 that indicate a fairly pragmatic culture (Hofstede, 2012). This means that both generalists and experts are needed because they focus on planning but can be change at short notice, emotions are not shown much, there is broad acceptance for new ideas or innovation, and people are generally willing to take a risk in trying something new (Hofstede, 2012). Finally, Australia scores 31 for Long-term Orientation that indicates a short-term oriented culture (Hofstede, 2012). As a result, the way Australians measure performance is based on short timeframes that make Australian people quick to show results.

In summary, both Indonesia and Australia are countries with multicultural aspects as evidenced by their diversity of ethnics, languages, and religions. However, in terms of Hofstede's cultural values, Indonesia and Australia is different especially for Power distance and Individualism dimensions.

\subsection{CONCEPTUAL FRAMEWORK}

Different national cultures will have different attitudes and behaviour (Hofstede, 2001). As McCorkle and colleagues (1999) said, that people from countries with high individualism will tend to work individually where people from countries with low individualism will likely to 
work in team. Based on Hofstede (2012), Australia scores 31 for power distance; 90 for individualism; 61 for masculinity; 51 for uncertainty avoidance; and 31 for long-term orientation. Meanwhile, Indonesia's score for power distance, individualism, masculinity, and uncertainty avoidance is $78,14,46$, and 48 respectively. This difference in national culture can result in different CQ and attitudes toward teamwork. For instance, students in Indonesia, as a country with low individualism, will be more likely to welcome working in teams than Australia. Based on this, the researcher hypotheses:

Hypothesis 1: There is significant difference between Indonesian and Australian students in terms of Cultural Intelligence variable Hypothesis 2: There is significant difference between Indonesian and Australian students in terms of Attitude towards Teamwork variable.

\subsection{METHODOLOGY}

\section{The Measurement Tools}

The researcher will use a questionnaire as a means to gather data. This method is in line with previous research in CQ (Ang et al., 2007; Scholl, 2009; Feyerherm \& Groves, 2011). This questionnaire will combine mini-CQS from Ang and Dyne (2008) for the CQ and the questions that are adapted from Kiffin-Petersen and Cordery (2003) for students' attitude towards teamwork. In addition, the questionnaire will be translated into Bahasa Indonesia and English to aid understanding.

The questionnaire uses close-ended questions as they are easier and quicker for respondents to answer and compare. At the same time, respondents are more likely to answer with fewer irrelevant and confused answers (Neuman, 2011). It is also easier for researchers to code and analyze the data, and replicate for future research (Neuman, 2011). The use of close-ended questions is appropriate in this research because many respondents are required, and the data produced allows utilization of statistical methods to analyze the relationship between variables.

Then, the questionnaire distributed in two forms; an internet-based questionnaire (IBQ) and a paper-based questionnaire (PBQ). The IBQ is advantageous for: accessing participants in many countries; less time consuming; lower cost; and reduces error when inputting data for analysis (Webb, Zimet, Fortenberry, \& Blythe, 1999; Wright, 2005; Neuman 2011). However, using IBQ runs the risk of target samples being unfamiliar with using the internet. Furthermore, it not possible to prevent anyone from filling in the IBQ more than once and to ascertain if anyone filling in the questionnaire is the target of interest. In addition, using IBQ further restricts the target population to only people with access to the internet (Webb et al., 1999; Wright, 2005; Neuman 2011).

Using PBQ curbs some of the issues faced by IBQ as it reduces the likelihood of respondents filling in the questionnaire more than once and it also removes the possibility of the target respondents not knowing how to use the internet to fill the questionnaire. Similar to IBQ, PBQ is able to reach a wide range of target samples and can be run on a large scale but the cost of PBQ might be higher. However, researchers must take caution in the transfer and coding of data as some questionnaires can be incompletely filled. Furthermore, it is more timeconsuming for both respondents and researchers to fill-in and mine the data (Wang et al., 2005; Lygidakis et al., 2010).

In this research, both the Australian students and the Indonesian students will be receiving the PBQ and the IBQ. As both ITB and Griffith provide internet connection for their students, it reduces the problem of respondents having no internet access. In addition, the IBQ will be sent directly to ITB students' mailing-list and will be posted to the internet course noticeboard of Australian students to ensure that respondents are in the target population. The PBQ will be distributed to Australian students in the classroom. The PBQ will be available for Indonesian students via a student service office on the ITB campus and students will be advised of this via email. Therefore, it will ensure that the questionnaire will be filled by target respondents. To get higher responses, target respondents are given the option to choose the preferred way of participation. All communications will advise students to only complete the survey once.

\section{Pre/pilot-test}

Before distributing the questionnaire to the respondents, the researcher first will distribute it to 5 students from each country to make sure that the questions are clear, easy to understand and to reduce ambiguity. Moreover, the questionnaire will be administered to 5 participants who know both Bahasa Indonesia and English language to reduce mistranslation. Pilot test also will be conducted once again in internet based questionnaire to make sure there are no differences between paper based and internet based questionnaire, also to check whether the interface is user-friendly. Based on the results from pilot-test, the researcher will adjust both the PQB and IBQ so it can meet the requirements to get the data that researcher needs. After that, the questionnaire is distributed to respondents.

\section{Participants}

In this research, there are two groups of respondents: Indonesian students which are defined as students in ITB; and Australian students which are defined as students in Griffith University. These groups of respondents are selected due to the multi-cultural exposure they engage in the university. There were 240 respondents in this research where the numbers of Australian students were 126 students; Indonesian students are 109 students; and five students that did not give information about their origin. However, even though there were students that did not give their information, but they still finished all the questions in questionnaire, therefore their data were still included in processing. From all those respondents, there were more females $(n=130)$ than males $(n=107)$ and three respondents that did not give their gender information. From those females, 76 respondents were Australian Students and 54 respondents were Indonesian students. Meanwhile, males' respondents were divided into 52 Australian students and 55 Indonesian students. All the 3 respondents that did not fill the information about their gender were coming from Australian students. The gender distributions of respondents were shown in table 1. 
Table 1 Gender distributions of respondents

\begin{tabular}{llll}
\hline & Australian students & Indonesian students & $\begin{array}{l}\text { All } \\
\text { respondents }\end{array}$ \\
\hline Male & $52(39.7 \%)$ & $55(50.5 \%)$ & $107(44.6 \%)$ \\
Female & $76(58 \%)$ & $54(49.5 \%)$ & $130(54.2 \%)$ \\
Blank & $3(2.3 \%)$ & $0(0 \%)$ & $3(1.2 \%)$ \\
Total & $131(100 \%)$ & $109(100 \%)$ & $240(100 \%)$ \\
\hline
\end{tabular}

Validity

Firstly, before the data was tested to find the correlation between variables, it was checked for its validity. In order to measure the validity of the data, this research used face validity and content validity. Face validity was done in pilot test and showed that items in both English and Indonesian version questionnaire showed clear meaning, understandable, no ambiguity, and there was no mistranslation from English to Indonesian. Therefore, in terms of face validity, the questionnaire used in this research was valid.

Moreover, mini-CQS was created based on four-factor model of CQ questionnaire develop by Ang et al. (2007) that already showed good validity, while for attitude towards teamwork, the scale was tested by Kiffin-Petersen and Cordery (2003) using Exploratory Factor Analysis (EFA) and showed good validity.

\section{Reliability}

Besides validity, the reliability of data also needs to be measured. The less error of data means the more reliable the data. In order to measures the reliability of data, this research used Cronbach's alpha $(\alpha)$ with all the data used (the combination of Indonesian and Australian students' responses). Depending on a number of factors, the normal 'rule of thumb' for the acceptance value of Cronbach's alpha are $<.60$ unacceptable, $.60-.65$ undesirable, $.65-.70$ minimally acceptable, $.70-.80$ respectable, $.80-.90$ very good, and $>.90$ consider shortening the scale by reducing the number of items (Everitt, 2002). The score of $\alpha$ for CQ $(\alpha=.792)$, and attitude towards teamwork ( $\alpha=.777)$ was in range $.70-.80$ which means respectable. Therefore, overall the reliability of data in this research was reliable.

\section{Mean and Standard Deviation}

For mean (M) and standard deviation (SD), data was divided into three categories. First,for All respondents, CQ has $\mathrm{M}=4.775$ and $\mathrm{SD}=$ 0.873 ) and attitude towards teamwork has $\mathrm{M}=4.420$ and $\mathrm{SD}=1.057)$. Second, for Australian students, $\mathrm{CQ}$ has $\mathrm{M}=4.591$ and $\mathrm{SD}=0.918$ ) and attitude towards teamwork has $\mathrm{M}=4.062$ and $\mathrm{SD}=1.156$ ). Lastly, Indonesian students, $\mathrm{CQ}$ has $\mathrm{M}=4.996$ and $\mathrm{SD}=0.763$ ) and attitude towards teamwork has $\mathrm{M}=4.851$ and $\mathrm{SD}=0.721$. The summary of mean and standard deviation can be seen in table 2 .

Table 2 Summary of mean and standard deviation of samples

\begin{tabular}{|c|c|c|c|c|c|c|}
\hline & \multicolumn{2}{|c|}{ Australian students } & \multicolumn{2}{|c|}{ Indonesian students } & \multicolumn{2}{|c|}{ All respondents } \\
\hline & Mean & Standard deviation & Mean & $\begin{array}{c}\text { Standard } \\
\text { deviatio } \\
\mathrm{n} \\
\end{array}$ & Mean & Standard deviation \\
\hline Cultural intelligence & 4.591 & .918 & 4.996 & .763 & 4.775 & .873 \\
\hline Attitude towards teamwork & 4.062 & 1.156 & 4.851 & .721 & 4.420 & 1.057 \\
\hline
\end{tabular}

\subsection{RESULTS AND DISCUSSION}

This research would find the difference between Australian and Indonesian students group in terms of each variable's value. For that, the data would be divided into two groups, first Australian students group $(\mathrm{n}=131)$, and second Indonesian students group ( $\mathrm{n}=109)$. The test will consist of Levene test that would check the equality between comparative variables and t-test to check the mean differences between groups. If the result of Levene test was significant $(\mathrm{p}<.05)$ then the equal variances not assumed which means there was variances difference between variables. Table 3 shows the result of Levene test

Table 3 Result of Levene test

\begin{tabular}{lll}
\hline & \multicolumn{2}{c}{ Levene's test for equality of variances } \\
\cline { 2 - 3 } & F & Sig. \\
\hline Cultural intelligence & 5.753 & 0.017 \\
Attitude toward teamwork & 17.668 & 0 \\
\hline \multicolumn{2}{r}{ Notes. Significant at 0.05 level $(p<0.05)$}
\end{tabular}

Based on the table 3 the Levene test indicated unequal variances for $\mathrm{CQ}(\mathrm{F}=5.753, \mathrm{P}<.05)$ and attitude towards teamwork $(\mathrm{F}=17.668, \mathrm{p}$ $<.05)$. Therefore, degree of freedom for CQ and attitude towards teamwork need to be adjusted when running t-test. The results of t-test are presented in table 4 
Table 4 Result of t-test

\begin{tabular}{|c|c|c|c|c|c|c|c|c|}
\hline & & \multicolumn{3}{|c|}{$T$-test for equality of means } & \multirow{3}{*}{$\begin{array}{l}\text { Mean } \\
\text { diff. }\end{array}$} & \multirow{3}{*}{$\begin{array}{l}\text { Std. Error } \\
\text { difference }\end{array}$} & \multirow{2}{*}{\multicolumn{2}{|c|}{$\begin{array}{l}95 \% \text { Confidence interval } \\
\text { of the difference }\end{array}$}} \\
\hline & & $\mathrm{T}$ & $\mathrm{df}$ & Sig. (2-tailed) & & & & \\
\hline & & & & & & & Upper & Lower \\
\hline $\begin{array}{l}\text { Cultural } \\
\text { intelligence }\end{array}$ & $\begin{array}{l}\text { Equal } \\
\text { variances not } \\
\text { assumed }\end{array}$ & 3.732 & 238.000 & 0.000 & 0.405 & 0.108 & 0.191 & 0.618 \\
\hline $\begin{array}{l}\text { Attitude toward } \\
\text { teamwork }\end{array}$ & $\begin{array}{l}\text { Equal } \\
\text { variances not } \\
\text { assumed }\end{array}$ & 6.449 & 221.639 & 0.000 & 0.789 & 0.122 & 0.548 & 1.030 \\
\hline
\end{tabular}

The result on t-test that shown in table 4 indicated that there was a significant difference for CQ $(\mathrm{t}(238)=3.732, \mathrm{p}<.05)$ for Australian group $(\mathrm{M}=4.591, \mathrm{SD}=0.918)$ and Indonesian group $(\mathrm{M}=4.996, \mathrm{SD}=0.763)$. Then, a significant difference was also showed by attitude towards teamwork $(\mathrm{t}(221.639)=6.449, \mathrm{p}<.05)$ for Australian group $(\mathrm{M}=4.062, \mathrm{SD}=1.156)$ and Indonesian group $(\mathrm{M}=4.851, \mathrm{SD}=$ $0.721)$.

\section{Discussion}

According to result of t-test, there was a significant difference between Australian and Indonesian students for CQ and attitude towards teamwork. In terms of CQ $(\mathrm{t}(238)=3.732, \mathrm{p}<.05)$, Indonesian students $(\mathrm{M}=4.996, \mathrm{SD}=0.763)$ showed higher mean than Australian students $(\mathrm{M}=4.591, \mathrm{SD}=0.918)$ which indicated that Indonesian students had higher CQ than Australian students. This difference could be due to the difference in the Individualistic culture for both countries which Australia scores 90 and Indonesia only 14 (Hofstede, 2012 ). High score of individualism indicated that Australia people most likely to take care themselves where lower score of individualism indicated that Indonesia people most likely to work together with other people (Hofstede, 2012). Because of that, Australian students might have less interaction with other students where the opposite might happen to Indonesian students. This difference in interaction could lead to the differences in adapting with other cultures. Moreover, due to the use of bahasa Indonesia as communication language, Indonesian students might face no difficulties to communicate each other. On the other hand, Australian students consisted of students from various countries, which some countries do not use English as their first language. This might lead to some difficulties in communication process. Therefore, hypothesis 1 was supported.

In line with differences in individualism, there was also a significant difference in attitude toward teamwork $(\mathrm{t}(221.639)=6.449, \mathrm{p}<$ $.05)$ between Indonesian students $(M=4.851, S D=0.721)$ and Australian students $(M=4.062, S D=1.156)$ where Indonesian students showed higher mean than Australian students. This indicated that Indonesian students had more positive attitude toward teamwork than Australian students. This situation could be happened due to high individualism in Australia that makes their people more independently than Indonesian with lower individualism. This was also related with masculinity in Australia that reached 61 which means that Australian people behave to successes and achieve high achievement because it becomes a basis for hiring and promotions in workplace, where Indonesia only reached 46 which means people value equality and have strong solidarity (Hofstede, 2012). Therefore, Australian people tend to have strong high achievement compared to Indonesian people. Meanwhile, people with strong high achievement could have better performance when they work individually (Freeman, 1996). Therefore, Australian students were likely to work independently rather than depend to other students. This result indicated that hypothesis 2 was supported.

\subsection{CONCLUSION}

The effect of globalization, that increases the utilization of multicultural teams, leads organizations and universities to become more aware of the importance of diverse teams. Working in teams can help employees and students to learn and experience how to deal with different people, to develop opinions and ideas, to learn to respect and trust others, and to work in collaborative ways. However, teams that consist of diverse members can have problems that are different than to working individually or working with members from similar cultural backgrounds. The ability to adapt and interact with different cultures, known as CQ, as well as the leadership style used are important factors that determine someone's attitude towards teamwork especially towards multicultural teams. This attitude towards teamwork can in turn affect the outcomes of the team process.

The results in this research showed there is a significant difference between Australian students and Indonesian students in terms of CQ and attitude towards teamwork. Indonesian students showed a greater mean than Australian students for all of these variables. This result was in line with the cultural differences between Australia and Indonesia especially the differences in Power distance, Individualism, and Masculinity. Therefore, hypotheses 1 and 2 were supported.

The results of this research contribute to filling the literature gap in several ways. First, this research used students as the sample, which is different to previous research that used employees as the sample. This provides a different perspective in terms of the effect of CQ and attitude towards teamwork. Second, this research used samples from two different cultures (Australia and Indonesia), which usually some previous research only focus on one particular culture, and compared it so it can be known the similarities and differences of variables in this research that occurred because of the cultural differences. Third, by using Australian and Indonesian students, this research enriches the body of knowledge of both Australia and Indonesia related to variables that used in this research.

Moreover, this research can also contribute to universities far planning their students' activities that require team process. The result and recommendation of this research can improve the quality of team process which can help both students and universities to get benefits from it. This research also can be a basis to future research in order to enrich the literature regarding of CQ and attitude towards teamwork. 


\subsection{RECOMMENDATION}

As the result indicated, both CQ and students' attitude towards teamwork have a significant different between Indonesian and Australian students. Therefore, universities need to consider those aspects when they plan the team activities.

In order to increase students CQ, some activities can be done. First, providing study tour trip to place with difference culture so the students can experience directly the culture differences; second, encouraging students to develop their CQ through assignments; Third, employed international faculty members so they could share their story about their native land to the students (McCrea \& Yin, 2012). For attitude towards teamwork factor, giving team building training to students and arrange team that make students feel comfortable (for example team where there is no dominant culture) can increase students' positive attitude towards teamwork. Another ways also can be done such as create booklets that give information about benefit of teamwork and various cultures as guidance in class activities.

Another factor to be considered is since Australian students have less CQ and attitude toward teamwork, then the intensity for activities to increase these aspects needs to be more intense compared to Indonesian students. For example, Australian students need to have more study trip to place with different culture than Indonesian students and have more team building training and activities.

\section{References}

Ang, S. \& Dyne, V.L. (2008). Handbook Of Cultural Intelligence: Theory, Measurement, And Applications. New York, NY: M. E. Sharpe

Ang, S., Van Dyne, L., Koh, C., Ng, K. Y., Templer, K. J., Tay, C. \& Chandrasekar, N. A. (2007). Cultural intelligence: Its measurement and effects on cultural judgment and decision making, cultural adaptation and task performance. Management and Organization Review, 3(3), 335-371.

Australian Bureau of Statistics.(2012). Retrieved October 9, 2012, from http://www.abs.gov.au/ausstats/abs@.nsf/Lookup/2071.0main+features902012-2013.

Ayoko, O. B., Härtel, C. E. J. \& Callan, V. J. (2002). Resolving the puzzle of productive and destructive conflict in culturally heterogeneous workgroups: A communication accommodation theory approach. International Journal of Conflict Management, 13(2), 165-195.

Baba, M. L., Gluesing, J., Ratner, H. \& Wagner, K. H. (2004). The contexts of knowing: Natural history of a globally distributed team. Journal of Organizational Behavior, 25(5), 547-587

Bianey C., Ulloa R. \& Stephanie G. (2004).Attitude toward teamwork and effective teaming. Team Performance Management, 10(7/8), 145-151.

Drach-Zahavy, A. (2004). The proficiency trap: How to balance enriched job designs and the team's need for support. Journal of Organizational Behavior, 25(8), 979996.

Earley, P. C. \& Ang, S. (2003). Cultural Intelligence: Individual Interactions Across Cultures. Stanford, Calif: Stanford University Press.

Earley, P. C. \& Mosakowski, E. (2000).Creating hybrid team cultures: An empirical test of transnational team functioning. The Academy of Management Journal, 43(1), 26-49.

Earley, P. C. \& Mosakowski, E. (2004).Cultural intelligence. Harvard Business Review, 82(10), 139

Eby, L. T. \& Dobbins, G. H. (1997). Collectivistic orientation in teams: An individual and group-level analysis. Journal of Organizational Behavior, 18(3), 275-295.

Ekelund, B. Z., Cerdin, J., Pekerti, A., Aycan, Z., Thomas, D. C., Au, K., Thomas, D. C., Elron, E., Stahl, G., Ravlin, E. C., Poelmans, S., Brislin, R., Maznevski, M., \& Lazarova, M. B. (2008). Cultural intelligence: Domain and assessment. International Journal of Cross Cultural Management, 8(2), 123-143.

Everitt, B. (2002). The Cambridge Dictionary Of Statistics. Cambridge: Cambridge University Press.

Feyerherm, A. E. \& Groves, K. S. (2011). Leader cultural intelligence in context: Testing the moderating effects of team cultural diversity on leader and team performance. Group \& Organization Management, 36(5), 535-566.

Freeman, K. A. (1996). Attitudes toward work in project groups as predictors of academic performance. Small Group Research, 27(2), 265-282.

Gardner, B., \& Korth, S. (1998). A framework for learning to work in teams. Journal of Education for Business, 74(1), 28-33.

Gelfand, M. J., Erez, M. \& Aycan, Z. (2007). Cross-cultural organizational behavior. Annual Review of Psychology, 58(1), 479-514.

Harrison, G. L., McKinnon, J. L., Wu, A. \& Chow, C. W. (2000). Cultural influences on adaptation to fluid workgroups and teams.Journal of International Business Studies, 31(3), 489-505.

Hofstede, G. (2012). Geert Hofstede National Culture.Retrieved September 16, 2012, from http://geert-hofstede.com/national-culture.html.

Hofstede, G. H. (2001). Culture's Consequences: Comparing Values, Behaviors, Institutions, And Organizations Across Nations. Thousand Oaks, Calif: Sage Publications.

Huddleston, P. \& Pfaff, E. (2003). Does it matter if I hate teamwork? what impacts student attitudes toward teamwork. Journal of Marketing Education, 25(1), 37-45.

Ingham, A. G., Levinger, G., Graves, J., \& Peckham, V. (1974). The ringelmann effect: Studies of group size and group performance. Journal of Experimental Social Psychology, 10(4), 371-384.

Jakarta Post. (2012). Racism remains for Chinese-Indonesians. Retrieved October 22, 2012, from http://www.thejakartapost.com/news/2012/01/22/racism-remainschinese-indonesians.html.

Johnson, D. W., Johnson, R. T. \& Smith, K. A. (1998). Cooperative learning returns to college. Change, 30(4), 26

Kaenzig, R., Hyatt, E. \& Anderson, S. (2007). Gender differences in college of business educational experiences. The Journal of Education for Business, 83(2), 95-100.

Kiffin-Petersen, S. \& Cordery, J. (2003).Trust, individualism and job characteristics as predictors of employee preference for teamwork. International Journal of Human Resource Management, 14(1), 93-116.

Kirkman, B. L. \& Shapiro, D. L. (2001). The impact of team members' cultural values on productivity, cooperation, and empowerment in self-managing work teams.Journal of Cross-Cultural Psychology, 32(5), 597-617.

Lawler, E. E. (1986). High-involvement Management. San Francisco, Calif: Jossey-Bass.

Lygidakis, C., Rigon, S., Cambiaso, S., Bottoli, E., Cuozzo, F., Bonetti, S., Bonetti, E., Bella, A. D., \& Marzo, C. (2010).A web-based versus paper questionnaire on alcohol and tobacco in adolescents. Telemedicine Journal and e-Health: The Official Journal of the American Telemedicine Association, 16(9), 925-930.

Man, D. C. \& Lam, S. S. K. (2003). The effects of job complexity and autonomy on cohesiveness in collectivistic and individualistic work groups: A cross-cultural analysis. Journal of Organizational Behavior, 24(8), 979-1001.

McCorkle, D. E., Kling, N. D., Iyer, R. V., Reardon, J., Alexander, J. F. \& Harris, R. C. (1999). Undergraduate marketing students, group projects, and teamwork: The good, the bad, and the ugly?Journal of Marketing Education, 21(2), 106-117.

McCrea, E. A. \& Yin, J. Z. (2012).Developing cultural intelligence: An undergraduate course assessment framework.Organization Management Journal, 9(2), 104.

Neuman, W. L. (2011). Social Research Methods: Qualitative And Quantitative Approaches. Boston, [Mass.]: Pearson.

Overview of Indonesia. (2012). Retrieved October 9, 2012, from http://www.expat.or.id/info/overview.html.

Pescosolido, A. T. (2001). Informal leaders and the development of group efficacy. Small Group Research, 32(1), 74-93.

Peterson, B. (2004). Cultural Intelligence: A Guide To Working With People From Other Cultures. Yarmouth, Me: Nicholas Brealey Publishing.

Ramamoorthy, N. \& Flood, P. (2002). Employee attitudes and behavioral intentions: A test of the main and moderating effects of individualism-collectivism orientations. Human Relations, 55(9), 1071-1096.

Randel, A. E. (2003). The salience of culture in multinational teams and its relation to team citizenship behavior. International Journal of Cross Cultural Management, 3(1), 27-44.

Sanchez-Burks, J., Nisbett, R. E. \& Ybarra, O. (2000). Cultural styles, relational schemas, and prejudice against out-groups.Journal of Personality and Social Psychology, 79(2), 174-189.

Scholl, D. H. (2009).The Relationship Between Cultural Intelligence And The Performance Of Multinational Teams.(Doctoral dissertation).Available from ProQuest Dissertations and theses database. (UMI No. 3381839). 
Thomas, D. C. (2006). Domain and development of cultural intelligence: The importance of mindfulness. Group \& Organization Management, 31(1), 78-99.

Waddell, D., George, J. M. \& Jones, G. R. (2011).Contemporary management. North Ryde, NSW: McGraw-Hill Australia.

Wang, Y., Lee, C., Lew-Ting, C., Hsiao, C. K., Chen, W. J. \& Chen, D. (2005). Survey of substance use among high school students in Taipei: Web-based questionnaire versus paper-and-pencil questionnaire.Journal of Adolescent Health, 37(4), 289-295.

Webb, P. M., Zimet, G. D., Fortenberry, J. D. \& Blythe, M. J. (1999).Comparability of a computer-assisted versus written method for collecting health behavior information from adolescent patients. The Journal of Adolescent Health : Official Publication of the Society for Adolescent Medicine, 24(6), 383-388.

Wright, K. B. (2005). Researching Internet-Based populations: Advantages and disadvantages of online survey research, online questionnaire authoring software packages, and web survey services.Journal of Computer-Mediated Communication, 10(3), 00-00.

Yuki, M., Maddux, W. W., Brewer, M. B. \& Takemura, K. (2005). Cross-cultural differences in relationship- and group-based trust.Personality \& Social Psychology Bulletin, 31(1), 48-62. 